\title{
Ritos genéticos editoriais \\ uma abordagem discursiva da edição de textos
}

\section{Luciana Salazar Salgado ${ }^{1}$}

\section{Resumo}

Este artigo aborda discursivamente o tratamento editorial de textos, propondo a noção de ritos genéticos editoriais para designar uma série de processos desencadeados pela leitura profissional do revisor de textos, uma atividade linguageira que define um lugar complexo, de atribuições opacas, condicionado e condicionante na dinâmica interlocutiva que revela. Com base nos fundamentos da análise do discurso de tradição francesa, procuramos avançar no entedimento das manobras de leitura e escrita envolvidas no preparo de um texto autoral destinado à circulação pública.

\section{Palavras-chave}

Discurso, alteridade, revisão de textos, ritos genéticos editoriais.

Recebido em 14 de maio de 2013

Aprovado em 10 de junho de 2013

SALGADO, Luciana Salazar. Ritos Genéticos Editorias: uma abordagem discursiva da edição de textos. Revista do Instituto de Estudos Brasileiros, Brasil, n.57, p. 253-276, 2013.

DOI: http://dx.doi.org/10.11606/issn.2316-901X.v0i57p253-276

1 Universidade Federal de São Carlos (UFSCar, São Carlos, SP, Brasil). 


\section{Editorial Genetic Rites \\ a Discursive Approach to Editing Texts Processes}

\section{Luciana Salazar Salgado}

\section{Abstract}

This article offers a discursive approach to the editorial treatment of texts, proposing the notion of editorial genetic rites to designate a series of processes unchained by a sort of professional reading, a language activity that defines a complex place, whose cloudy attributions arise from the dynamics of interlocution. Based on discourse analysis of French tradition, we look for to advance in the understanding of the maneuvers involved on this reading-and-writing activity witch characterizes the preparation of a text to its public circulation.

\section{Keywords}

Discourse, otherness, text revision, editorial genetic rites. 


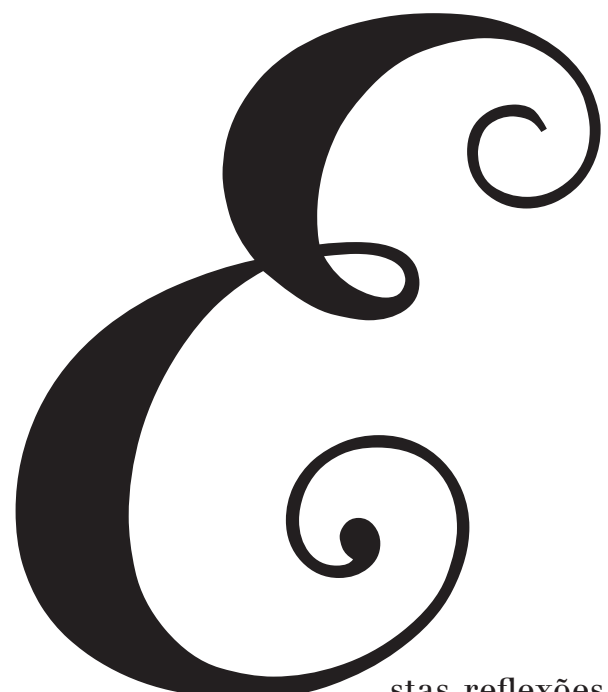

Introdução ao problema

stas reflexões fazem parte de um programa de pesquisa desenvolvido sob a rubrica Escritas profissionais e processos de edição. Nesta ocasião, propomos examinar aspectos da alteridade constitutiva do lugar de autor, evidenciando o lugar de um leitor bastante específico: o revisor de textos, que conjuga, em seu trabalho de leitura, um esboço de leitores futuros e a função de duplo autoral.

Esse lugar abriga dinâmicas próprias, conforme os tipos de texto que passam por tratamento editorial e as instituições em que esses textos se produzem e se preparam para circular mais amplamente. De fato, trata-se de uma atividade que não consiste apenas na aplicação objetiva de protocolos, tais como a prescrição gramatical normativa, para citar um dos aspectos mais fortemente ligados aos imaginários de revisão de textos; por isso, nos parece imprescindível abordá-la nas suas condições de emergência, na dinâmica social e histórica em que se inscreve. Dessa perspectiva, uma questão fundamental logo se põe: o que é mercado editorial do ponto de vista discursivo?

Em linhas gerais, um mercado é sempre um ambiente de trocas; abordar essas trocas do ponto de vista discursivo implica, então, procurar nas discursivizações os nós e ligaduras que permitem reconhecer um conjunto de entidades e de procedimentos identificados como responsáveis por essas trocas. Implica, assim, considerar tanto os dizeres daqueles que as estudam, criticam ou com elas dialogam mostrando distância, quanto os dizeres dos que se põem como parte integrante desse ambiente. Nesta altura, é preciso considerar, ainda, que se tem falado em coletivos criativos, em re-trabalho, em remix, em sampler... notadamente nas artes plásticas e na música, mas toda produção cultural tem hoje, mais intensamente do que noutros tempos, que se haver com essas questões. No caso dos textos escritos, essas 
discussões também estão diretamente ligadas às representações da autoria; juridicamente, deve-se levar em conta uma série de formulações que pretendem regular a propriedade intelectual: como julgar uma apropriação indébita? Como entender as conexões entre direitos do criador e acesso ao bem cultural?

Para pensar essa problemática em termos de lugares, isto é, em termos de identidades sociais firmadas historicamente e manifestadas em práticas que se reiteram, procurando legitimar-se, valemo-nos de recentes desdobramentos da análise do discurso de tradição francesa, assentados nas noções de que a língua é constitutivamente opaca e polissêmica, os sujeitos são clivados, e as conjunturas de interlocução são marcadas por lugares sociais definidos na sobreposição de temporalidades de que se faz a história. Essa análise do discurso vê nos textos, ou melhor, nas práticas de textualização, as marcas da heterogeneidade e da alteridade constitutivas de todos os dizeres. Vê, assim, a relação ininterrupta entre intradiscurso e interdiscurso.

Sobre essas bases, propomos o estudo do funcionamento discursivo que preside o preparo de textos destinados à circulação pública. E, então, é preciso lembrar que estão compreendidas aí tanto as práticas generalizadas nas casas editoras, quanto outras, menos oficiais mas igualmente generalizadas, dos próprios autores, que frequentemente tomam a iniciativa de contratar uma revisão de textos antes mesmo de submeter seu material à apreciação de uma editora. E é preciso levar em conta também que, se por um lado esse tipo de trabalho se intensificou recentemente e tem cada vez mais características peculiares ao nosso tempo (afinidades com a tecnologia informática, com a aceleração de processos dela decorrente e com as urgências de produtividade e competitividade que impelem a alimentação desse ciclo), por outro, é herança de uma longa história que remonta a práticas anteriores até mesmo ao formato códex moderno, na medida em que revela o quanto o original de um autor, no longo processo que o transforma em publicação, movimenta-se, passando por diferentes olhares e cuidados.

O trabalho de edição de textos que vem se estabelecendo no mercado editorial parece, assim, um “ofício de linguista”, na medida em que não bastam "sensibilidade textual", como a têm muitos free lancers que atuam no mercado de revisões, ou "rigor formal", como costumam cultivar muitos dos professores de gramática que prestam serviços de revisão de provas para editoras. Num mundo de aceleração dos ritmos e de multiplicação de tudo o que se oferece ao consumo (como as publicações), o tratamento de textos parece exigir algo além do gostar de ler, do prazer de trabalhar com textos e do estrito conhecimento da gramática. 
Cada vez mais esses profissionais assumem trabalhos especializados em condições de execução peculiares ${ }^{2}$.

Em termos da Classificação Brasileira de Ocupações ${ }^{3}$, o Ministério do Trabalho e Emprego (MTE) organiza descrições de atividade profissionais por famílias, que são conjuntos de ocupações estabelecidos pelo reconhecimento de semelhanças características de um domínio de trabalho, mais amplo do que cada ocupação. É uma tentativa de prever flexibilidades asseguradas por algum rigor de definição. Na atual versão, há uma família de "Profissionais da escrita", bastante extensa e considerada próxima das chamadas famílias afins "filólogos, intérpretes e tradutores" e "editores". Reproduzimos o quadro inicial de descrição desses profissionais tal como figura no endereço eletrônico do MTE:

\begin{tabular}{|c|c|}
\hline 2615-05 - & $\begin{array}{l}\text { Autor-roteirista - Adaptador de obras para teatro, cinema e televisão, } \\
\text { Argumentista-roteirista de história em quadrinhos, Autor-roteirista } \\
\text { de cinema, Autor-roteirista de rádio, Autor-roteirista de teatro, Autor- } \\
\text { roteirista de televisão, Autor-roteirista multimídia, Dramaturgista }\end{array}$ \\
\hline $2615-10-$ & $\begin{array}{l}\text { Crítico - Crítico de artes plásticas, Crítico de cinema, Crítico de dança, } \\
\text { Crítico de jornal (ombudsman), Crítico de música, Crítico de rádio, } \\
\text { Crítico de teatro, Crítico de televisáo, Crítico literário }\end{array}$ \\
\hline 2615-15 - & $\begin{array}{l}\text { Escritor de ficção - Autor de ficção, Contista, Cronista de ficção, } \\
\text { Dramaturgo, Ensaista de ficção, Escritor de cordel, Escritor de folhetim, } \\
\text { Escritor de histórias em quadrinhos, Escritor de novela de rádio, Escritor } \\
\text { de novela de televisão, Escritor de obras educativas de ficção, Fabulista, } \\
\text { Folclorista de ficção, Letrista (música), Libretista, Memorialista de } \\
\text { ficção, Novelista (escritor), Prosador, Romancista }\end{array}$ \\
\hline $2615-20$ - & $\begin{array}{l}\text { Escritor de não ficção-Biógrafo, Cronista de não ficção, Enciclopedista, } \\
\text { Ensaista de não ficção, Escritor de obra didática, Escritor de obras cien- } \\
\text { tíficas, Escritor de obras educativas de não ficção, Escritor de obras } \\
\text { técnicas, Folclorista de não ficção, Memorialista de não ficção }\end{array}$ \\
\hline 2615-25 - & Poeta-Letrista, $\operatorname{Tr}$ \\
\hline
\end{tabular}

2 MUNIZ Jr., José de Souza. O trabalho com o texto na produção de livros: os conflitos da atividade na perspectiva ergodialógica. 2010. 179 f. Dissertação (Mestrado em Teoria e Pesquisa em Comunicação). Escola de Comunicações e Artes, Universidade de São Paulo, 2010.

3 “A CBO é o documento que reconhece, nomeia e codifica os títulos e descreve as características das ocupações do mercado de trabalho brasileiro. Sua atualização e modernização se devem às profundas mudanças ocorridas no cenário cultural, econômico e social do País nos últimos anos, implicando alterações estruturais no mercado de trabalho." Disponível em: <http://www.mtecbo.gov.br>. Acesso em: 25 out. 2013 . 


\begin{tabular}{|c|c|}
\hline $2615-30-$ & $\begin{array}{l}\text { Redator de textos técnicos - Glossarista, Redator de anais, Redator } \\
\text { de jornal, Redator de manuais técnicos, Redator de textos cientificos, } \\
\text { Redator de textos comerciais }\end{array}$ \\
\hline
\end{tabular}

\section{Descrição sumária}

Escrevem textos literários para publicação, representação e outras formas de veiculação e para tanto criam projetos literários, pesquisando temas, elaborando esquemas preliminares. Podem buscar publicação ou encenação da obra literária bem como sua divulgação.

Segundo essas descrições, trata-se de entender os profissionais da escrita como autores. Mas quando se prossegue no documento, conforme os desdobramentos da descrição sumária, chega-se a outro quadro - o que define as áreas de atividade:

\section{ESCREVER TEXTOS}

\begin{tabular}{|c|}
\hline Adequar linguagem ao público-alvo \\
\hline Utilizar recursos retóricos para sedução dos leitores \\
\hline Decodificar a obra para o público-alvo \\
\hline Escrever de acordo com as especificidades do gênero da obra \\
\hline Elaborar e reelaborar o texto \\
\hline Justificar as ideias apresentadas no texto técnico, didático e científico \\
\hline Refazer o livro didático periodicamente \\
\hline Apresentar relatórios do desenvolvimento do trabalho \\
\hline Reelaborar o texto final considerando pareceres críticos \\
\hline
\end{tabular}

Evidentemente, há aí uma expansão da noção de autoria.

Adiante, nesse mesmo documento, no item que define as competências pessoais, lê-se:

Competências pessoais 1 Demonstrar hábito de leitura 2 Demonstrar criatividade 3 Desenvolver intuição 4 Demonstrar senso de observação 5 Dominar a língua 6 Dominar a linguagem específica do veículo (tv, livro, cinema, teatro, jornal etc.) 7 Negociar contrato de edição 8 Discutir direitos autorais 9 Participar de comissões julgadoras

E, para circunscrever essas competências, somos levados a checar as famílias afins: 


\section{4: Filólogos, intérpretes e tradutores}

\begin{tabular}{|c|c|}
\hline $2614-05-$ & Filólogo - Crítico textual, Filólogo dicionarista \\
\hline $2614-10-$ & $\begin{array}{l}\text { Intérprete - Intérprete comercial, Intérprete de comunicação eletrô- } \\
\text { nica, Intérprete de conferência, Tradutor simultâneo }\end{array}$ \\
\hline 2614-15 - & $\begin{array}{l}\text { Lingüista - Lexicógrafo, Lexicólogo, Lingüista dicionarista, } \\
\text { Vocabularista }\end{array}$ \\
\hline $2614-20-$ & $\begin{array}{l}\text { Tradutor - Tradutor (exclusive público juramentado), Tradutor } \\
\text { de textos eletrônicos, Tradutor de textos escritos, Tradutor público } \\
\text { juramentado }\end{array}$ \\
\hline
\end{tabular}

\section{Descrição sumária:}

Traduzem, na forma escrita, textos de qualquer natureza, de um idioma para outro, considerando as variáveis culturais, bem como os aspectos terminológicos e estilísticos, tendo em vista um público-alvo específico. Interpretam oralmente, de forma simultânea ou consecutiva, de um idioma para outro, discursos, debates, textos, formas de comunicação eletrônica e linguagem de sinais, respeitando o respectivo contexto e as características culturais das partes. Tratam das características e do desenvolvimento de uma cultura, representados por sua linguagem; fazem a crítica dos textos.

\section{6: Editores}

\section{6-05- Editor de jornal}

\begin{tabular}{|l|l|l|}
\hline 2616-10- & Editor de livro
\end{tabular}

2616-15- $\quad$ Editor de mídia eletrônica

2616-20- Editor de revista

2616-25- Editor de revista científica

\section{Descrição sumária}

Editam textos e imagens para publicação e, para tanto, selecionam o que publicar, definem pauta e planejamento editorial, coordenam o processo de edição, pesquisam novos projetos editoriais, gerenciam editoria e participam da divulgação da obra. Responsabilizam-se pela publicação.

E, afinal, somos levados a procurar pelos ofícios produtor de texto e revisor, que aqui encontramos sem definição estendida: 


\section{1: Profissionais do jornalismo}

\begin{tabular}{|c|c|}
\hline 2611-05- & Arquivista pesquisador (jornalismo) \\
\hline 2611-10 - & Assessor de imprensa \\
\hline $2611-15-$ & Diretor de redação - Diretor adjunto \\
\hline $2611-20-$ & $\begin{array}{l}\text { Editor - Editor assistente, Editor de área, Editor de arte, Editor de } \\
\text { fotografia, Editor de imagem, Editor de rádio, Editor de web, Editor } \\
\text { executivo }\end{array}$ \\
\hline $2611-25-$ & $\begin{array}{l}\text { Jornalista - Assistente de editorial, Colunista, Colunista de jornal, } \\
\text { Correspondente de jornal, Correspondente de linguas estrangeiras, } \\
\text { Cronista, Diarista-em jornal, Diretor noticiarista, Editorialista, } \\
\text { Jornalista exclusive empregador, Jornalista-empregador, } \\
\text { Radiojornalista, Roteirista de jornal, Roteirista na imprensa }\end{array}$ \\
\hline 2611-30 - & Produtor de texto \\
\hline $2611-35-$ & $\begin{array}{l}\text { Repórter (exclusive rádio e televisão) - Repórter cinematográfico, } \\
\text { Repórter correspondente, Repórter de área, Repórter de web, Repórter } \\
\text { especial }\end{array}$ \\
\hline 2611-40 - & Revisor \\
\hline
\end{tabular}

\section{Descrição sumária}

Recolhem, redigem, registram através de imagens e de sons, interpretam e organizam informações e notícias a serem difundidas, expondo, analisando e comentando os acontecimentos. Fazem seleção, revisão e preparo definitivo das matérias jornalísticas a serem divulgadas em jornais, revistas, televisão, rádio, internet, assessorias de imprensa e quaisquer outros meios de comunicação com o público.

Como se vê, por aproximações é que podemos delinear o que se vem entendendo dessa atividade, de como ela participa da divisão do trabalho intelectual. Por ora, registremos que, segundo a perspectiva aqui assumida, o profissional que trabalha sobre os textos autorais não opera como coautor; antes, produz um descentramento do texto-primeiro que permite ao autor ser um outro desse outro de si, que faz anotações pontuais como quem deixa rastros a ser seguidos. Nessas trilhas de leitura explicitada, são feitas correções gramaticais, estabelecem-se padrões e seguem-se normas, mas esse trabalho vai muito além da idéia de corrigir, padronizar e normalizar. 


\section{Redigir um texto, enunciar; editar um texto, coenunciar}

Para avançar nestas reflexões sobre o lugar do revisor de textos, termo que subsume uma quantidade bastante variável de atribuições ${ }^{4}$, propomos refinar o quadro teórico mobilizado na direção de uma análise do discurso de base enunciativa, aqui convocada sobretudo por meio das formulações de Authier-Révuz, especialmente quando estuda as relações entre heterogeneidade mostrada e heterogeneidade constitutiva, e, com base nelas, nos apresenta concepcões como as não-coincidências do dizer, a autorrepresentação opacifiante do dizer, as palavras que não são óbvias e as palavras mantidas a distância ${ }^{5}$. São essas noções que desenvolve ao tratar de um paradoxo discursivo fundamental a que chama conflito solidário, no qual nos deteremos.

A expressão conflito solidário aparece num artigo de 1990, “A não-coincidência interlocutiva e seus reflexos metaenunciativos", no qual Authier-Révuz discute mecanismos e estratégias de identificação ou, antes, de construção da identidade enunciativa, uma ilusão de autonomia assentada na porosidade da condição de sujeito: os sujeitos se instituem à medida que procuram colmatá-la.

Segundo a autora, não se trata de supor que é desejável superar a clivagem original. Ao contrário, trata-se de entender o quão necessária é a ilusão de sujeito que, a despeito de sempre deixar ver menos ou mais explicitamente a clivagem que há, mostra-se ao apontar seu outro, e assim é que constitui a enunciação. Dessa perspectiva, enunciar é emergir no emaranhado interdiscursivo exercitando polêmicas e apropriações definidoras de um um.

Um ponto central nessa teoria é o de que há palavras que não se bastam, que não são óbvias e demandam modalizações autonímicas, indicadoras da heterogeneidade discursiva. As formas marcadas dessa heterogeneidade são designadas como registros das não-coincidências do dizer: enunciados que, procurando ser algo "donos de si”, falam sobre si mesmos, menos ou mais explicitamente, ressalvando-se, recompondo-se, enfatizando partes, minimizando impactos supostos, remetendo o interlocutor a conjuntos de preceitos ou reflexões, enfim, rearranjando-

4 Cf. YAMAZAKI, Cristina. Edição de textos na produção editorial de livros: distinções e definições. 2007. 231 f. Dissertação (Mestrado em Ciências da Comunicação). Escola de Comunicações e Artes, Universidade de São Paulo, São Paulo, 2007.

5 AUTHIER-RÉVUZ, Jacqueline. Entre a transparência e a opacidade: um estudo enunciativo do sentido. Vários tradutores, revisão de tradução Leci Barbisan; Valdir Flores. Porto Alegre: EDIPUCRS, 2004.

6 Idem, ibidem, p. 81-103. 
-se na sua expressão. Nesses rearranjos - construções gestoras de efeitos de esclarecimento, de distanciamento, de autocorreção ou de adequação contingente - evidencia-se a inextricabilidade entre o linguístico e o não-linguístico, além do caráter heterogêneo de toda discursividade. Segundo Authier-Revuz, esse recurso a rearranjos de partes de um enunciado faz crer que há transparência noutras partes, pois, numa ressalva à adequação de um termo ou numa gradação que busca um "melhor dizer", reside a suposição de que outros termos ou outras passagens do enunciado valem por si, dizem o que devem dizer.

Ao supor que parte de um enunciado demanda uma nota que sobre ele lance luz, o enunciador confere à matéria linguística um caráter de esclarecível e, com isso, atribui a todo o resto do enunciado um caráter de já esclarecido. Daí se desdobra uma importante discussão sobre o sujeito e a assunção de que instâncias extralinguísticas também se entrelaçam nos dizeres, em diferentes percursos, com base nos quais se realiza toda a atividade linguageira. Pensando no sujeito como enunciador dessas modalidades recursivas, Authier-Revuz fala em heterogeneidade constitutiva e heterogeneidade mostrada. A primeira refere-se a uma característica do primado do interdiscurso: todo dizer, sendo um fio de discurso, faz-se contraponto ou retoma um já-dito, antes e alhures. A segunda refere-se à localização alusiva com a qual um enunciador dá a saber "seu" lugar, que se delimita segundo o enunciador e por não ser nenhum outro, ou seja, (de)negando outros lugares que, rejeitados, delimitam o seu.

Assim, considerando o dialogismo bakhtiniano, as discussões relativas ao discurso como produto do interdiscurso e a psicanálise lacaniana, Authier-Revuz refuta qualquer atribuição meramente subjetiva à construção da identidade enunciadora, na qual heterogeneidade constitutiva e heterogeneidade mostrada representam realidades distintas: uma, a dos processos de constituição de um discurso; a outra, a dos processos de representação, num discurso, de sua constituição. Ambas conflitam, posto que a constitutiva devolve toda enunciação ao interdiscurso de que emerge, deixando-a "sem dono", e a mostrada insiste na demarcação do que não é e, portanto, do que é, numa pretendida garantia autoral. É esse conflito que produz um equilíbrio sistêmico nas situações de enunciação, e faz com que elas sejam efetivamente situações de enunciação, estabelecendo sujeitos em troca, cadeias semânticas em relação, discursos formalizados, dizíveis.

Authier-Revuz nos propõe uma classificação dessas não-coincidências, formulações que, no material linguístico, autorrepresentam um dizer e, ato contínuo, seu enunciador. Essas não-coincidências nos 
permitem entender que as palavras, ao não se bastarem, no jogo de demarcações que viabiliza um discurso, seu enunciador e toda sorte de elementos conexos à sua enunciação, produzem sobre si mesmas notas que as referendam na sua discursividade. As palavras que não são óbvias, na constituição dinâmica dos discursos, configuram aparatos de interação com os quais o um se "defende" de tudo que passa a ser, então, o não-um. Nos termos da autora, configuram verdadeiras panóplias moventes.

A calibragem dessas panóplias é o que caracteriza a atividade de revisão de textos ou, melhor dizendo, o tratamento editorial de textos. É nessa calibragem que o revisor de textos se institui, conjugando as posições de um leitor-primeiro do autor-origem e de um duplo do autor-deslocado. É nos interstícios desses processos de legitimação e de tolhimento que se pode procurar ver as instituições discursivas funcionando e fazendo funcionar. Nos conflitos solidários, conforme a expressão de Authier-Revuz, se escoram as balizas que permitem reconhecer que há discursividades e também que suas dimensões e alcances escapam, derivam. Afinal, "sendo o discurso da ordem do acontecimento, é o lugar das instabilidades das categorias linguísticas estabilizadas no sistema”, mas "dizer que as categorias se instabilizam no discurso não significa admitir que elas se realizam aleatoriamente. Ao contrário, essas instabilidades obedecem a certas coerções, que são garantia mesma da existência do sentido" .

Desse modo, o trabalho dos autores e de seus coenunciadores autorizados, ou seja, textualizações que se tecem no cotidiano do mercado editorial, de certo modo escancaram a alteridade discursiva, enfatizando a dinâmica sistêmica dos diversos movimentos constitutivos de um texto, que, passando por esse processo, ainda assim será publicado sob o nome de um autor, porque seguirá sendo um texto desse autor.

A definição desse um, autor-dono-do-texto, tanto melhor se define quanto mais abertamente marca seu outro, sendo que o outro não é qualquer um, mas aquele que é imprescindível não ser; nesses termos, o tratamento editorial de textos é uma possível confirmação da autoria, na medida em que é um exercício de alteridade explicitado pelo trabalho do coenunciador editorial, que se põe como um outro do autor ainda no processo autoral; lê antes da publicação, "ensaia” interlocuções futuras, aponta caminhos e descaminhos que enxerga no texto, mas não pode

7 FIORIN, José Luiz. Polifonia textual e discursiva. In: BARROS, Diana Luz Pessoa de; FIORIN, José Luiz (orgs.). Dialogismo, polifonia, intertextualidade. São Paulo: Edusp, 1999. p. 33 . 
pretender padronizar o traço distintivo, digamos, as singularidades que caracterizam um autor.

Em todo caso, não se trata de buscar a singularidade como traço de uma autonomia pessoal, da liberdade plena de um indivíduo capaz de exercê-la: "a ilusão de liberdade discursiva se situa no fato de que o texto é individual. O discurso simula ser meu naquilo que, em si, não tem sentido, o plano da expressão"; é nos modos de dizer que reside a singularidade, que só tem sentido porque se dá numa circunstância de enunciação: os modos de dizer são elaborados num dado lugar discursivo. Buscar nas textualizações os indícios de autoria supõe, portanto, considerar "que, acima de qualquer outra coisa, um texto ser bom ou ruim tem mais a ver com o como do que com o quê"9.

Historicamente, não se trata de acudir em favor da volta do Autor outorgando-lhe os poderes de que foi inteiramente destituído por muitos estudos estruturalistas, por exemplo, mas de entender que todo "sujeito de discurso' está inscrito na materialidade do texto, na maneira como ele aponta seu autor"10, que a condição de autor é:

Característica do modo de existência de circulação e de funcionamento dos discursos no interior de uma sociedade, e, por esse motivo, a reflexão sobre autoria não pode estar desvinculada da discussão sobre os regimes de apropriação dos textos e da construção da memória coletiva de uma sociedade. ${ }^{11}$

Vista assim, a autoria supõe sempre sujeitos trabalhando, enunciadores que "deixam suas marcas nos objetos que produzem."12 O que não significa dizer que o autor, figura central, seja o soberano do que diz. Possivelmente, ele dá o tom e talvez reja a banda, mas também ele dança conforme a música.

$\mathrm{O}$ autor é sempre dependente e reprimido:

8 Idem, ibidem, p. 35 .

9 POSSENTI, Sírio. Indícios de autoria. Perspectiva, Florianópolis: UFSC, v. 2o, n. 1, p. 106, jan.-jun. 2002.

10 GREGOLIN, Maria do Rosário. Sentido, sujeito e memória: com o que sonha nossa vã autoria?. In: GREGOLIN, Maria do Rosário; BARONAS, Roberto Leiser (orgs.). Análise do discurso: as materialidades do sentido. São Carlos: Claraluz, 200z. p. 47-58. (p. 49)

11 Idem, ibidem.

12 POSSENTI, Sírio. (1999) O sujeito e a distância de si no discurso. In: Os limites do discurso. Curitiba: Criar, 2002b, p. 123-135. (p. 128) 
Dependente: ele não é o mestre do sentido, e suas intenções expressas na produção do texto não se impõem necessariamente nem para aqueles que fazem desses textos um livro (livreiros-editores ou operários da impressão), nem para aqueles que dele se apropriam para a leitura. Reprimido: ele se submete às múltiplas determinações que organizam o espaço social da produção literária, ou que, mais comumente, delimitam as categorias e as experiências que são as próprias matrizes da escrita. ${ }^{13}$

Isso nos remete às condições de produção: todas as etapas do tratamento gráfico que o material recebe no percurso editorial (impresso ou virtual) podem ser entendidas também como parte da criação, da composição, da construção de um livro. E isso vale inclusive para a etapa de revisão de provas, em que aspectos mais estritamente formais como normalizações, padronizações, correções de digitação e congêneres são observados na sua consonância com as condicionantes materiais, como capa, ilustração, diagramação das páginas, formato de notas, recursos de destaque etc. Tudo isso faz parte da identidade de uma publicação; tudo isso é processo de tessitura, são ritos constitutivos de um objeto editorial que jamais coincide com os originais do autor.

Em Gênese dos discursos (1984), Maingueneau usa a expressão ritos genéticos para se referir "ao conjunto de atos realizados por um sujeito em vias de produzir um enunciado"14, procurando formular uma noção mais ampla do que a de pré-texto, proposta por BelleminNoël em Le texte et l'avant texte, que pretendia, por sua vez, ampliar a noção de rascunho. Maingueneau inclui nesse conjunto os documentos escritos, os rascunhos e esboços, e também comportamentos não escriturais como viagens e meditações, enfim, toda uma sorte de ações de pesquisa ou preparo (coleta, checagem, visita, entrevista etc.) diretamente envolvidas com uma dada produção escrita. Diz Maingueneau que seria um equívoco "ver nesses ritos apenas uma relação pessoal e inefável entre um autor e sua escritura, uma pura inspiração", afinal "aí também o discurso define suas restrições" ${ }^{15}$. Ritos pessoais se conjugam a ritos impostos, sendo que essa diferenciação é apenas uma tentativa de entender como "a vocação enunciativa supõe harmonização mais ou menos estrita entre as práticas individuais do autor e as representações

13 CHARTIER, Roger. (1999) Cultura escrita, literatura e história. Trad. Ernani Rosa, consultoria e revisão técnica Ilza Jardim. Porto Alegre: ARTMED, 2001. (p. 35-36)

14 MaingueneaU, Dominique. Gêneses do discurso. Trad. Sírio Possenti. Curitiba: Criar, 2005. p. 139.

15 Idem, ibidem. 
coletivas nas quais ele se reconhece e que comunidades mais ou menos amplas verão, por sua vez, encarnadas nele"16.

Em 2005, Maingueneau retoma a noção de ritos genéticos desenvolvendo uma série de tópicos já tratados ou apenas mencionados ao longo destes vinte anos de pesquisa desde Gênese. Parece muito interessante observar que essa noção ressurge com força explicativa de processos ligados às práticas dos escritores, a suas relações com os chamados coletivos técnicos, às materialidades que um texto escrito pode assumir, às condições do jogo entre discursos no mercado da produção intelectual. Sobre esse tipo de reflexão, que tem norteado muitos trabalhos em diversos campos de saber, diz Peter Jaszi:

Certamente seria útil examinar como o autor se tornou individualizado numa cultura como a nossa [ocidental], que status lhe foi conferido, em que momento os estudos de autenticidade e atribuição de autoria começam, em que tipo de sistema de valores a figura de autor foi envolvida, em que ponto começamos a recontar as biografias dos autores em vez das histórias de heróis e como se instituiu essa categoria fundamental da "crítica do homem e seu trabalho"17.

Para abarcar as produções intelectuais que vê como coletivos criativos, Jaszi põe relevo sobre o que chama work-for-hire - que podemos entender aqui tanto como as encomendas de editores, muito frequentes no caso de coleções de livros didáticos, técnicos, de autoajuda e congêneres, e também em traduções, inclusive literárias; quanto as "encomendas" das carreiras profissionais. São bastante conhecidas as exigências relativas à publicação de trabalhos dos professores e pesquisadores acadêmicos, tanto nas universidades públicas como nos centros universitários privados e fundações, e também de profissionais da saúde não acadêmicos e mesmo de executivos, sobretudo no que tange aos temas administrativos e de marketing. Em diversas profissões, hoje, a autoria de textos públicos é, se não uma exigência, uma possibilidade (principalmente com os baixos custos de publicação na internet) que pode conferir notoriedade ao profissional e benefícios dela decorrentes.

16 Idem, ibidem, p. 140.

17 WOODMANSEE, Martha \& JASZI, Peter (eds.). (1994) The Construction of Authorship - Textual Appropriation in Law and Literature. London: Duke University Press, 2oo6. p. zo. 
Diante disso, podemos nos perguntar sobre a "marca autoral" ou sobre a "originalidade" que, afinal, são reconhecidas em certos textos e não o são em outros. Maingueneau formula, para tratar disso, o lugar da autoria como paratópico ${ }^{18}$. Com essa noção, aborda os ritos genéticos: “o escritor original é de fato obrigado a inventar ritos genéticos na medida da sua necessidade"19, estabelecendo uma espécie de enlaçamento: “é preciso já ter encontrado os ritos genéticos pertinentes para elaborar as obras, mas é o êxito das obras realizadas que consagra a pertinência desses ritos" ${ }^{20}$. Assim, entende-se que os mitos construídos em torno do trabalho dos autores - malditos, nobres, eremitas, sábios, detentores de segredos, didáticos, generosos... - valem hoje para os escritores de todos os tipos de publicação, ou quase todos, posto que todas essas produções intelectuais se encontram - e até mesmo, em alguns casos, se confundem - no mercado de trocas.

Nesses termos é que podemos falar em criação. Em uma criação que tem a ver com o trabalho sobre os sentidos produzíveis nos textos, que não são autotélicos nem mensagem de uma instância supra-humana. Desse modo, os ritos genéticos são gestos conjuradores, na medida em que constroem um lugar social que, espera-se, deve legitimar essa construção:

Esses ritos constituem, na verdade, o único aspecto da criação que ele [escritor autor] pode controlar, a única maneira de conjurar o espectro do fracasso. Em matéria de criação, o êxito é profundamente incerto: como se assegurar de que se fez uma obra de valor quando nem mesmo a aprovação do público imediato é um critério seguro? Não resta ao autor senão multiplicar os gestos conjuradores, mostrar a si mesmo e ao público os sinais de sua legitimidade (p. 156). ${ }^{21}$

18 Essa noção está desenvolvida privilegiadamente sobre o Discurso literário em MaIngueneaU, Dominique. Discurso literário. Trad. Adail Sobral. São Paulo: Contexto, 20o6. Aqui, recorremos a uma célebre formulação de Nietzsche sobre esse "lugar paralelo" sobre o qual se erige a possibilidade do trabalho de criação autoral: "um Homero não teria criado um Aquiles, um Goethe não teria criado um Fausto, se Homero tivesse sido Aquiles, e Goethe um Fausto" NIETZSCHE, Friedrich. (1887) Genealogia da Moral. Trad., notas e prefácio Paulo César de Souza. São Paulo: Companhia das Letras, 1998. p. 91.

19 MaingueneaU, Dominique. Discurso literário. Op. cit., p. 157.

20 Idem, ibidem.

21 Idem, ibidem, p. 156. 
Com base nisso, e contemplando o que foi dito sobre as formas de circulação dos livros, vemos o trabalho que é feito sobre os textos autorais que se preparam para ir a público como ritos genéticos editoriais, especificando a noção de Maingueneau, sem jamais perder de vista que se trata de ritos de uma gênese discursiva, ou seja, sem perder de vista que o trabalho do coenunciador editorial, assim como o do autor e de todos os que lidam com seu texto, é feito de um dado lugar discursivo.

\section{Sobre tessitura e textura}

Essa alteridade amplificada nos ritos genéticos editoriais parece enfatizada no termo textualização, com que se procura abarcar a condição dinâmica dos textos, na qual um conjunto de práticas alimenta os sistemas em que elas se instituem. Lembremos que, aqui, o texto interessa como lugar de movimentos semânticos orientados, como espaço de ressonâncias e reverberações de caráter histórico, como material linguístico atravessado por um exterior que lhe é constitutivo, como trabalho de sujeitos. Visto assim, podemos imaginar duas dimensões da textualização: tessitura e textura.

Tessitura designa uma dimensão mais dinâmica do trabalho, da atividade linguageira, de seus aspectos mais movediços e em progressão, sua condição de abertura a recomposições. Textura designa uma dimensão mais diretamente ligada aos efeitos de sentido produzidos, logo, aos aspectos mais estabilizados ou estabilizantes, à condição de unidade. Assim, tessitura e textura são termos que procuram dar conta dos processos de produção e interpretação, simultâneos e implicados. Para examinarmos esse aspecto da alteridade marcada num trabalho em progressão, seguese um dado. Nele, autores replicam anotações e convocam a tréplica do coenunciador editorial.

Descrição do dado - excertos de um livro que reúne especialistas e não-especialistas em torno do tema infância, adolescência e AIDS, compilando depoimentos de pessoas diretamente envolvidas com o trabalho cotidiano de assistência a crianças e adolescentes vivendo ou convivendo com HIV/AIDS e arrazoados de estudiosos e organizadores da luta pela contenção da epidemia.

A interlocução discursiva está bastante evidente: a organizadora (também autora) da obra coletiva convida um colega a interagir com o responsável pelo tratamento editorial. O diálogo caminha sem nunca fechar o texto; ao contrário, sugere-se sempre, estribados nas observações desencadeadas pelas notas do coenunciador, que ele mesmo decida sobre "os rumos da prosa". 
O documento eletrônico pesquisado utilizava as seguintes cores: magenta para as correções gramaticais e outras mudanças na malha textual, azul para dúvidas do coenunciador editorial, vermelho para o colega convidado a participar, verde para a organizadora. Por razões técnicas, as intervenções serão apresentadas todas em negrito, as réplicas estão em preto sem destaque, introduzidas por uma barra (/) para o convidado e duas barras (//) para a autora organizadora. Os nomes próprios foram substituídos.

\section{Excerto I}

O aprendizado coletivo nos leva, finalmente, a sugerir alguns princípios orientadores para a área de infância, adolescência e aids, que são: 1) trabalhar pela garantia dos Direitos Humanos como perspectiva norteadora de ações governamentais e não-governamentais direcionadas à população infanto-juvenil vivendo e convivendo com HIV/AIDS; 2) priorizar políticas públicas que articulem ações de prevenção e assistência em diferentes esferas (saúde, educação, assistência social ${ }^{5}$, justiça) e (...)

5 Não sei se no jargão da área isso é claro, mas, em princípio, a saúde, a educação e a justiça de que se fala aí são formas de assistência a crianças e adolescentes. "Assistência" sozinha refere-se a algum apoio ou serviço específico? /Concordo, acho que devemos tirar. //SILVIA, Acho conveniente deixar porque no Brasil temos o serviço publico dividido em segmentos saúde educ.justiça, assistência social que no caso deste debate é importante.O túlio tinha concordado porque como ele não é brasileiro não se antenou para este detalhe, mas pode colocar assistência social.

Ao modo de um fórum (aliás, os textos reunidos nessa obra são registros dos fóruns de que os autores vêm participando ao longo de anos), os organizadores/autores debatem uma solução para o problema levantado: o que é essa categoria "assistência social"? É a reunião de assistência à saúde, à educação e à justiça ou, num dado campo de saber, emersa de dadas práticas, assistência social pode assumir um sentido outro?

Túlio (o convidado) concorda com a categorização proposta por Sílvia (coenunciador editorial), mas Ilda (autora e organizadora) explica por que discorda dessa categorização: 1. de seu lugar (especialista, uma 
das organizadoras da obra e dos fóruns que discutem o tema) apresenta um conhecimento específico - as divisões do serviço público no Brasil preveem essa departamentalização, 2. informa Sílvia de que Túlio não é brasileiro e por isso (provavelmente) não se antenou para esse detalhe. Fica clara a condição histórica e social da produção dos sentidos: aqui, depende da inserção numa dada sociedade - a brasileira -, num certo momento histórico - hoje em dia -, num certo setor - a saúde pública.

A interferência do interlocutor editorial não altera a redação final, portanto. Mas penetra numa discussão relevante, chamando a atenção dos organizadores para uma categoria e possivelmente para divergências entre eles até então insuspeitadas.

\section{Excerto II}

Em 1996, com a implementação do chamado coquetel de medicamentos antiretrovirais, pudemos obter um maior controle da doença, tanto do ponto de vista da medicina quanto da qualidade de vida de adultos e crianças ${ }^{8}$. O uso dos medicamentos aumentou a expectativa de vida e, desde esse ano, as mortes e as doenças ocasionadas pela aids têm diminuído significativamente no Brasil (Ministério da Saúde do Brasil, 2002b).

8 Em que medida essa "qualidade de vida" é algo diferente do "ponto de vista da medicina"? Esta é a introdução da publicação, nenhum aprofundamento sobre isso foi feito e a saúde, para o senso comum, pelo menos, está incluída na idéia de "qualidade de vida". /Acho bom, então, colocar uma nota aclaratória ou aclarar dentro do texto da forma seguinte: Se for nota: O ponto de vista médico significa a visão da instituição médica e o ponto de vista da qualidade de vida significa a experiência de vida das pessoas vivendo com HIV/AIDS. Se for no texto: controle da doença, tanto da perspectiva das instituições médicas quanto das experiências de vida de crianças e adultos vivendo com HIH/AIDS.//SILVIA eu gosto mais da sugestão de incluir no texto, veja como pode ficar bom, por favor

Há padronizações editoriais. A primeira delas, ao se atribuir o recurso itálico a coquetel de medicamentos antiretrovirais. Esse marcador gráfico pode ter várias funções e, aqui, parece ligado ao fato de se estar introduzindo uma referência que recorrerá em toda a obra, algo que deve ser lido como uma expressão, um sintagma, uma unidade de sentido. A segunda padronização editorial são as letras minúsculas 
em aids, que parecem refletir a opção por um recurso gráfico que evita o visual poluente das maiúsculas (uma diretriz editorial bastante frequente), mas talvez se pudesse considerar também esta interpretação: as minúsculas tornam mais comum a AIDS que, grafada como sigla em caixa alta, parece ganhar um destaque indesejável nesse contexto.

Na nota 8, levanta-se um problema de categorização: o que são "o ponto de vista da medicina" e "qualidade de vida"? Na formulação do interlocutor editorial, é possível inferir um pressuposto: em Em que medida essa "qualidade de vida" é algo diferente do "ponto de vista da medicina"? depreende-se que, em princípio, são coisas iguais ou pelo menos não-diferentes e, se forem diferentes, o serão em alguma medida. E parece que levanta uma questão crucial (que nos remete mais uma vez às coerções dos gêneros do discurso). Registra: Esta é a introdução da publicação, nenhum aprofundamento sobre isso foi feito..., alegando um certo procedimento a seguir e instituindo a necessidade de uma decisão filosófica e epistemológica - a saúde, para o senso comum, pelo menos, está incluída na idéia de "qualidade de vida", uma afirmação baseada em uma certa memória discursiva.

A relevância dessa intervenção é clara: Túlio e Ilda estão de acordo com a reformulação que visa categorizar os termos, e aí a questão genérica também se coloca: se for nota, há uma proposta que esclarece as duas categorias (ponto de vista da medicina e qualidade de vida); se for no texto, propõe-se uma substituição, "qualidade de vida" passa a controle da doença, tanto da perspectiva das instituições médicas quanto das experiências de vida de crianças e adultos vivendo com HIVIAIDS.

Mas permanece ainda uma questão, que não é sobre essas categorias, reformuladas sem assombro. Pela mão dos organizadores, volta para seu interlocutor editorial a decisão sobre como pode ficar bom. Não basta ter opções bem formuladas para a tessitura, uma para a inserção de uma nota e outra para o corpo do texto, é preciso decidir sobre qual dos recursos será mais adequado à textura. Decisão confiada a Sílvia, agora munida de informações que os autores apresentam como balizas para uma finalização.

\section{Excerto III}

Nesse sentido, estabelecemos uma parceria com o GEISHGrupo Interdisciplinar de Sexualidade Humana da Faculdade de Educação da UNICAMP e, sem nenhum financiamento ${ }^{6}$, viabilizamos um curso mensal para representantes de 15 instituiçõe 
s ligadas ao Fórum. Nesses encontros, temos realizado leituras e debates sobre temas como concepções de infância, adolescência, sexualidade, relações de gênero, adesão aos medicamentos, revelação do diagnóstico, elaboração de projetos, trabalho voluntário, papel do adulto, participação e ações educativas junto à população atendida. O curso contribuiu para a adesão de mais pessoas ao GT, para o fortalecimento do grupo e permitiu que pudéssemos delinear as iniciativas para 2004.

6 Este parece um dado tão relevante, no contexto de luta e dificuldades que descreveram até aqui, que fica estranho ser apenas um comentário em passant Como é que se "viabilizou" a iniciativa? Penso que quem vai ler estes textos está interessadíssimo em saber coisas desse tipo.// Que engraçado ve perguntar isso, a gente tira tanto leite de pedra que nem se lembra de falar das coisas. Talvez pudesse colocar um rodapé. A verdade é que amolei tantos meus colegas da unicamp e eles são tao sensíveis que vieram dar o curso de graça ,acredita? Mas daí no segundo ano escrevi um projeto incluindo o livro e o curso e conseguimos recursos .Enfim, acho que podemos colocar uma nota de rodapé. O primeiro ano do curso foi realizado sem financiamento contando com a colaboração voluntária dos membros do geish e de cada ONG que financiou o almoço e transporte de seus membros. No segundo ano do curso obtivemos financiamento do PE DST AIDS que[...]

Na nota do coenunciador, registra-se uma preocupação com a luta e com o público que vai ler estes textos, suposto como interessadíssimo em saber coisas desse tipo. Essa preocupação se coloca justamente no que diz respeito à progressão do texto - Este parece um dado tão relevante, no contexto de luta e dificuldades que descreveram até aqui, que fica estranho ser apenas um comentário en passant. Ao que um dos organizadores responde ratificando a pertinência da questão: a gente tira tanto leite de pedra que nem se lembra de falar das coisas. E, então, sugerese que Talvez pudesse colocar um rodapé - decisão que será delegada ao interlocutor editorial, que saberá dizer melhor o que se deu a saber. Pode-se dizer que há uma partilha, marcada pelo grau de informalidade com que certos dados aparecem, por exemplo: A verdade é que amolei tantos meus colegas da universidade e eles são tao sensiveis que vieram dar o curso de graça, acredita?. Esse enunciado não é uma proposta de ajuste da malha textual, mas uma informação que deve encaminhar a tessitura. 
Nesse momento, a criança é ouvida por seus amigos e aprende a ouvir também. Muitas atividades podem ser feitas em roda: contar novidades, fazer circular sacos-surpresa, criar fantasias, ouvir músicas, soprar bolinhas de sabão, partilhar brinquedos trazidos de casa e até simples conversas, coisas do dia-a-dia que as crianças adoram falar, por exemplo: do seu final de semana, da sua casa, quem chupa chupeta ou toma mamadeira, quem faz xixi na cama ou novidades do mundo, como os coalas da Austrália e a extinta arara azul brasileira?

7 Ela não foi extinta. $O$ trabalho de pesquisa, manejo e conservação da espécie vem sendo desenvolvido pela equipe da bióloga Neiva Guedes, do Projeto Arara Azul. /Muito bom, poderiamos mudar para o risco de extinção da //que ótimo! Vc é uma revisora que sabe das coisas...acho bom em risco de extinção.Tanta coisa que a Arara me escapou.

Para encerrar esta breve análise, reproduzimos um excerto em que quase todas as marcas cinza são correções gramaticais, o que seria uma tarefa básica de um revisor, mas é a nota 7 que destacamos: nela se verifica que não cabe mesmo a quem edita os textos definir a versão a ser publicada. Se assim fosse, uma informação falsa ou errônea - a de que a arara azul está extinta - poderia ser sumariamente cortada. Mas as noções de autoria e de texto com que trabalha o coenunciador conduzem, mais uma vez, a um diálogo; informa-se que a arara azul é objeto de um programa de manejo e conservação, e com base nisso é que se debatem soluções. Chama a atenção o entusiasmo com que os organizadores recebem o registro. Uma solução possível é oferecida por Túlio e ratificada por Ilda, que acaba fazendo uma observação específica sobre o trabalho - Você é uma revisora que sabe das coisas... E não importa se Sílvia conhecia o dado ou fez uma pesquisa; em ambos os casos, ela "sabe das coisas" porque ocupou um lugar textualizando sua legitimação.

Ilda ainda registra uma observação sobre sua própria condição de organizadora-autora e, no limite, sobre o próprio processo de escritura, que partilha, numa reflexão metadiscursiva jocosa: Tanta coisa que a Arara me escapou. Essa passagem nos permite inferir que está selada aí a confiança na tessitura que produz a textura a ser publicada.

Possivelmente, podemos dizer que, na cadeia criativa do livro, autor e coenunciador editorial são ambos escribas com funções 
distintas. E nesse trabalho conjunto de textualização, que parece viver uma tendência a acentuar-se, novas formas de escritura se impõem, mas também se preservam lugares fundamentais. A atual discussão sobre direitos autorais e propriedade intelectual diz respeito a isso: de um lado, o acirramento da fiscalização e da punição ao que se tem classificado como pirataria; de outro lado, o licenciamento chamado copyleft, opondo-se ao copyright ${ }^{22}$, e o sistema creative commons ${ }^{23}$ propõem direitos não-restritivos, facultando aos autores e detentores de patentes a liberação de certas formas de circulação de suas obras ou produtos - ou seja: facultando-lhes um posicionamento político a partir de sua função autoral, que é também uma função social.

De todo modo, importa aqui observar que a etapa editorial de trabalho com os textos não é um acabamento, embora vá nessa direção. Mesmo num texto correto, do ponto de vista gramatical, com a fluência de uma escrita experiente, há reparos a fazer, porque em todo texto há sempre brechas para deriva. Portanto esse trabalho sobre os textos não pode pretender evitar tais fendas, frestas e desvios, mas, ao apontar alguns deles, pode gerir taticamente a textualização, marcando certos caminhos como preferenciais, possibilitando, com esses apontamentos, uma distância do escriba autor em relação a seu texto, qualificando sua leitura, garantindo-lhe os traços de sua autoria. Isso acontece porque esses escribas trabalham numa dimensão discursiva: formas de dizer são postas em questão e, com isso, necessariamente os próprios dizeres.

22 Copyleft é um trocadilho nascido com o software livre: as produções intelectuais têm autores, mas eles entendem que suas produções devem circular, ser partilhadas e modificadas colaborativamente. Em vez de copyright - all rights reserved, propõe-se copyleft - all rights reversed. Há muita discussão sobre o que representa politicamente esse "deixa-se copiar" (= copyleft). Para os que se engajam nesse tipo de disseminação das obras, trata-se de um posicionamento colaborativo, contrário ao não-colaborativo dos softwares codificados. A idéia é que o conhecimento não se reduza à condição de mercadoria, escapando às manipulações das leis do mercado financeiro e dos interesses das grandes corporações (http://www.comciencia.br, último acesso fev.2007).

23 Com base na idéia de copyleft, o creative commons, uma rede global de colaboração intelectual e artística, foi elaborado por Lawrence Lessig e proposto à sociedade civil pelas Universidades de Stanford e Harvard (Estados Unidos). Trata-se de uma caixa de ferramentas administrável pelos próprios produtores de conteúdo intelectual, de modo que autorizem formalmente certos usos de suas obras. O sistema legal em vigor atualmente supõe que qualquer uso é proibido, a menos que o artista ou autor autorize cada um deles, em geral cobrando por isso. O sistema creative commons pretende ser uma autorização legal anterior a cada uso que se fará, sendo que essa autorização tem gradações definidas pelo detentor dos direitos. (http:// www.direitorio.fgv.br, último acesso mai.2013). 
O que há de singular num texto e aparecerá aos futuros leitores como "estilo do autor" é construído ou consolidado aí.

Enfim, considerando que tessitura e textura são dimensões inseparáveis de uma unidade discursiva textualizada, ou seja, constituem o que vimos chamando de textualização, podemos pensar que a figura do autor está mais diretamente ligada à textura, e sua participação na tessitura desencadeia a trajetória que se processará editorialmente; já o trabalho dos coenunciadores editoriais está mais diretamente ligado aos movimentos de tessitura, funciona como uma certa luz lançada, inclusive, sobre as autorrepresentações do dizer autoral. Trata-se de uma leitura que explicita esse descentramento, de modo que o autor também possa ser um leitor de seu texto e, enfim, que a versão oferecida a futuros leitores enseje consistentemente sua legitimidade, acolhendo desde os ritos genéticos a alteridade que toda publicação pretende suscitar quando circula.

\section{Considerações finais}

O estudo das relações entre tessitura e textura permite avançar no entendimento da força das discursividades cosendo uma rede de práticas que são o vivido, a construção social. Estudá-las requer que se considerem os modos de dizer, isto é, os materiais textuais como centro de movimentos complexos de entrelaçamento do linguístico com o não-linguístico, dos enunciados com suas formas de emergência e de transmissão. Nesses termos, publicar textos - manuais, reflexões filosóficas, discussões científicas, crônicas, novelas... - é um modo de pôr a energia social em movimento.

Nessa dinâmica, diversos lugares discursivos se põem como pontos nodais de uma rede. O lugar de autor é um deles, é um móbil de certas trocas. O lugar de coenunciador editorial é outro, conexo ao de autor. Dele, um leitor profissional oferece ao autor a explicitação da interlocução que todo texto supõe (e, no caso das publicações, pretende), e o autor pode tomar distância de seu texto, voltando a ele para produzir uma versão pública consistente. É um ofício de “catar feijão”, para nos valermos da imagem de João Cabral, autor que aprecia o engenho fino dos dizeres e a força dessa luta.

Diz o poeta que, ao catar feijão, como ao escrever, é preciso jogar fora o que boiar, mas diz ele, também, que o que não é feijão e afunda com os grãos, no caso dos textos, precisa de outra consideração: os textos não devem pretender ser pura mastigação digerível. O oficio de escrever supõe sempre que haverá trabalho de um outro, isto é, que um outro 
correrá umas linhas, tardará noutras e é provável que tropece lá e cá, pois o encontro entre sujeitos é sempre no caminho, caminhantes que são os sujeitos ao se porem nas cenas de enunciação (e as leituras, como as escrituras, são modos de pôr-se nessas cenas).

De fato, a cada nova leitura esse processo se reinicia em alguma medida. Provavelmente por isso há tantos textos engavetados, que nunca ficam prontos, porque um texto só está pronto quando se decide que vai circular, e não quando se crê ter chegado a uma versão efetivamente definitiva. Os textos, linearizações de discursos, não têm fim. Por definição. E os ritos genéticos editoriais não são outra coisa senão a celebração disso, do modo como a criação é obra de um esforço permanente de múltiplas miúdas engrenagens.

\section{Sobre a autora:}

\section{Luciana Salazar Salgado}

Professora Adjunta do Departamento de Letras da UFSCar. Graduada em Letras (Francês e Português) pela Faculdade de Filosofia, Letras e Ciências Humanas da Universidade de São Paulo (FFLCH - USP). Mestre em Educação pela Faculdade de Educação da USP (FE-USP) e doutora em Linguística pelo Instituto de Estudos da Linguagem da Universidade Estadual de Campinas (IEL - Unicamp). Pós-doutorado no Departamento de Linguística da FFLCH-USP com bolsa Fapesp.

E-mail: lucianasalazarsalgado@gmail.com 